\title{
Synergistic Interaction of Tri- and Tetra- Chloroethylene, Hypoxia, and Ethanol on the Atrioventricular Conduction of the Perfused Rat Heart
}

\author{
Tsuyoshi KAWAKAMI*, Takehito TAKANO* \\ and Ryuichiro ARAKI** \\ * Department of Public Health and Environmental Science, \\ Tokyo Medical ana Dental University Faculty of Medicine, \\ Yushima, Bunkyo-ku, Tokyo 113, Japan \\ ** Department of Hygiene, Saitama Medical School, \\ Moroyama-cho, Iruma-gun, Saitama 350-04, Japan
}

(Received September 10, 1987 and in revised form December 4, 1987)

\begin{abstract}
The interactions of trichloroethylene (TCEL) or tetrachloroethylene (perchloroethylene; PCEL) with hypoxia and/or ethanol on the conduction system of the isolated perfused rat heart were investigated by recording the direct electrocardiogram (ECG). The coadministration of TCEL $(0.05 \mathrm{mM})$, hypoxia $(45 \%$ oxygen decrease), and ethanol $(0.3 \%)$ produced the significant prolongation of atrioventricular conduction time (PQ interval) $(p<0.01)$, whereas none of TCEL $(0.05 \mathrm{mM})$ alone, hypoxia alone, ethanol alone, hypoxia with ethanol, TCEL with hypoxia, and TCEL with ethanol caused significant change in ECG findings. In TCEL of $0.1 \mathrm{mM}$, the coadministration with hypoxia and/or ethanol produced the significant prolongation of $P Q$ interval $(p<0.01)$. In PCEL of $0.1 \mathrm{mM}$, only when hypoxia and ethanol were coadministered simultaneously, PQ prolongation observed was significant $(p<0.01)$. It is concluded that $(1)$ TCEL and PCEL have the direct and local effect on the heart conduction system; (2) the effect on the heart conduction system is stronger in TCEL than in PCEL; (3) hypoxia and ethanol synergistically enhance the effect of TCEL and PCEL on the atrioventricular conduction system at the observed concentrations.
\end{abstract}

Key words: Trichloroethylene - Tetrachlorethylene - Hypoxia - Ethanol - Atrioventricular conduction-Perfused rat heart

\section{INTRODUCTION}

Trichloroethylene (TCEL), a widely used organic solvent in the industrial fields for metal degreasing and extraction purposes, is known to have the toxicity to heart as well as to the various organs such as liver, kidney, and nervous system., ${ }^{1,2}$ Descriptions on the severe arrhythmia such as ventricular fibrillation and cardiac arrest during and after TCEL inhalation are found in several case reports. $^{3-11)}$ 
Tetrachloroethylene (perchloroethylene; PCEL) is another common industrial solvent for dry-cleaning and degreasing. Although little experimental data relating to the effect on the heart conduction system of PCEL exist, the evidence has been shown to indicate the proarrhythmic action of this compound. Abedin et al. reported that a dry-cleaning worker had the frequent ventricular premature beats by PCEL inhalation. ${ }^{12)}$ An epidemiological study on the Japanese dry-cleaning workers revealed an excess of deaths relating to heart diseases. ${ }^{13)}$

It has been known that hypoxia influences the conduction of the cardiac impulse. ${ }^{14,15)}$ The interaction of hypoxia with an organic solvent, monofluoromethane, was also reported ${ }^{16)}$ although little is known on the interaction of hypoxia with TCEL or PCEL.

Ethanol also affects the heart conduction system. Cardiac rhythm disorders associated with alcohol drinking was clinically reported. ${ }^{1 i}$ ) Experimentally, it has been shown that ethanol influences the heart conduction system. ${ }^{18-20}$ ) The interaction of ethanol with TCEL on the heart conduction system has also been suggested. White et al. observed that ethanol potentiated epinephrine-induced cardiac arrhythmias in rabbit exposed to TCEL. ${ }^{21)}$

Thus, in the present study, we examined the interactions of TCEL/PCEL, ethanol and hypoxia on the heart conduction system by recording the direct electrocardiogram (ECG) of the perfused rat heart, which has been accepted as a simple and advantageous experimental method for evaluating the direct cardiac effect of chemicals. ${ }^{22,23)}$

\section{Materials ANd Methods}

\section{Animals}

Eighty-six male Wistar rats (Clea Japan, Inc., Tokyo), 9-10 weeks of age, were used in the present study. The animals were fed with chow diet (Clea Japan, Inc., Tokyo) and water ad libitum.

\section{Chemicals}

Purified TCEL and PCEL containing no stabilizers, were purchased from Nakarai Chemicals Ltd. (Kyoto, Japan). Gas chromatography was used to determine the purity of TCEL and PCEL, which was $>99.5 \%$. All other chemicals were of analytical grade.

\section{Hemoglobin-free isolated hearts perfusion}

After decapitation, the hearts were quickly removed and mounted onto a steel cannula through aorta, and the perfusate started to flow. Duration of time for the setting was within 1 minute. The perfusion apparatus was a modified method of Langendorff and the aortic pressure was kept constant at $80 \mathrm{~cm}$ water. The perfusate was not recycled in a flow-through system and its temperature was 
maintained at $31^{\circ} \mathrm{C}$. The flow rate was $6-8 \mathrm{ml} / \mathrm{min}$. The perfusate was KrebsHenseleit bicarbonate buffer, equilibrated with a gas mixture of $95 \%$ oxygen $/ 5 \%$ carbon dioxide (oxygen-saturated perfusate). Through the previous study, it is confirmed that oxygen consumption of the perfused rat heart is kept constant and the cardiac tissue is kept normoxic within one hour. ${ }^{23)}$ After 15 minutes preperfusion, the hearts were subjected to one of the following conditions: normoxia (95\% oxygen $/ 5 \%$ carbon dioxide) (control), hypoxia alone (45\% oxygen decrease), ethanol alone $(0.3 \%)$, hypoxia and ethanol, TCEL of $0.05 \mathrm{mM}$ alone, TCEL $(0.05$ $\mathrm{mM})$ with hypoxia, TCEL $(0.05 \mathrm{mM})$ with ethanol, TCEL $(0.05 \mathrm{mM})$ with hypoxia and ethanol, TCEL of $0.1 \mathrm{mM}$ alone, TCEL $(0.1 \mathrm{mM})$ with hypoxia, TCEL $(0.1 \mathrm{mM})$ with ethanol, TCEL $(0.1 \mathrm{mM})$ with hypoxia and ethanol, TCEL of $0.3 \mathrm{mM}$ alone, TCEL of $0.5 \mathrm{mM}$ alone, PCEL of $0.05 \mathrm{mM}$ with hypoxia and ethanol, PCEL of $0.1 \mathrm{mM}$ alone, PCEL $(0.1 \mathrm{mM})$ with hypoxia, PCEL $(0.1 \mathrm{mM})$ with ethanol, and PCEL (0.1 $\mathrm{mM})$ with hypoxia and ethanol.

\section{Administration and measurement of agents}

TCEL, PCEL, and ethanol were dissolved in Krebs-Henseleit bicarbonate buffer and introduced into the perfusion circuit with feeder pumps. The final concentrations of TCEL and PCEL in the perfusate in the circuit were checked with a gas-chromatograph. Hypoxic condition was subjected by changing the oxygen-saturated perfusate into the perfusate saturated by $50 \%$ oxygen $/ 45 \%$ nitrogen $/ 5 \%$ carbon dioxide. The oxygen concentration in the perfusate in the circuit was checked with a Clark-type oxygen electrode.

\section{Electrocardiogram}

Electrocardiogram was measured through the electrodes directly attached to the aortic root and the posterior wall of the left ventricle of the heart, and recorded by a pen oscillograph (NEC San-ei instrument, Ltd., Tokyo). The prolongation of $\mathrm{PQ}$ intervals (PQ intervals at 45 minutes exposure minus preexposure $P Q$ intervals) was used as the indicator to evaluate the effects on the heart conduction system. In order to assess the relation with heart rate, the prolongation of $P Q$ intervals divided by heart rate at 45 minutes $(\mathrm{dPQ} / \mathrm{HR})$ was used as another indicator.

\section{Statistical analysis}

Data were analyzed by three way analysis of variance. If analysis of variance indicated a significant difference, Student's $t$-test was applied. 


\section{RESUlTS}

In 86 rats used in the present study, the mean preexposure atrioventricular conduction time was $43.3 \pm 0.4 \mathrm{msec}$ (mean \pm S.E.), and the mean preexposure heart rate was $152.3 \pm 2.3$ beats per minute. In normoxia (control), neither atrioventricular conduction time nor heart rate at 45 minutes showed significant differences from the preexposure values. None of hypoxia alone, ethanol alone, and hypoxia and ethanol elicited significant PQ prolongation (Fig. 1). In heart rate, hypoxia alone and hypoxia and ethanol caused significant decreases (Table).

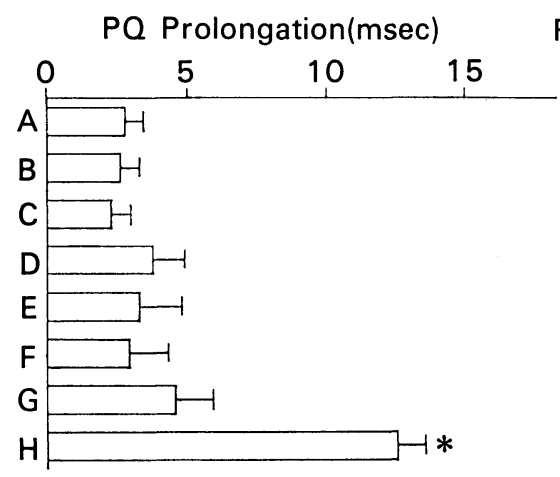

Fig. 1

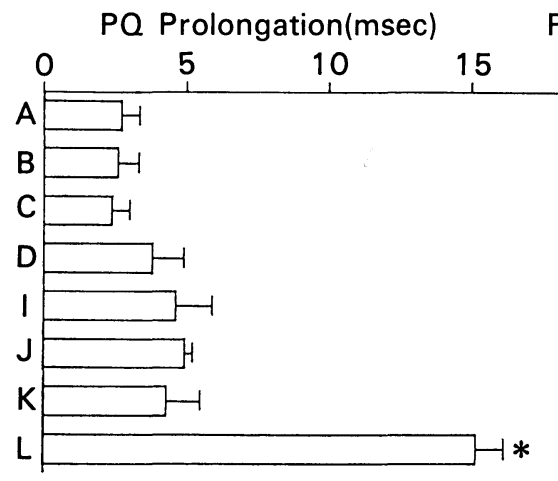

Fig.3
PQ Prolongation/Heart Rate(msec/beats/min)

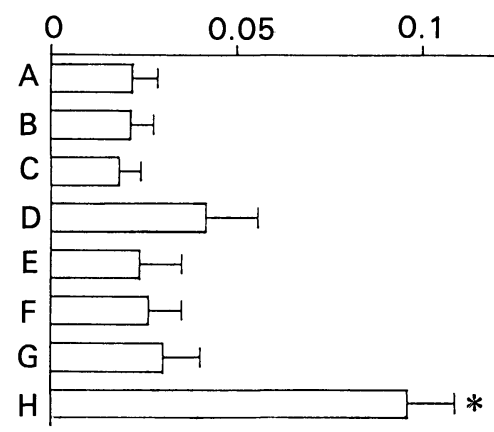

Fig. 2

PQ Prolongation/Heart Rate(msec/beats $/ \mathrm{min})$

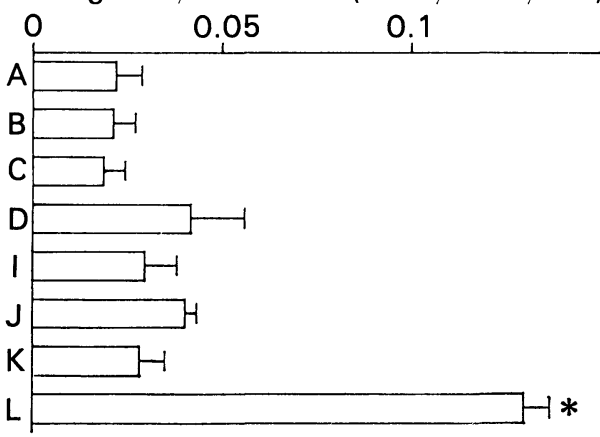

Fig.4

Fig. 1-4. Changes in atrioventricular conduction. Prolonged PQ intervals (PQ intervals at 45 minutes minus preexposure $P Q$ intervals) (Fig. 1, 3) and the prolonged PQ intervals divided by heart rates at 45 minutes (Fig. 2, 4) are shown. (A) normoxia (control); (B) hypoxia alone; (C) ethanol alone; (D) hypoxia and ethanol; (E) TCEL $(0.05 \mathrm{mM})$ alone; (F) TCEL (0.05 mM) with hypoxia; (G) TCEL (0.05 mM) with ethanol; (H) TCEL (0.05 $\mathrm{mM}$ ) with hypoxia and ethanol; (I) PCEL (0.1 mM) alone ; (J) PCEL $(0.1 \mathrm{mM}$ ) with hypoxia; (K) PCEL (0.1 mM) with ethanol; (L) PCEL (0.1 mM) with hypoxia and ethanol. Each value represents the mean \pm S.E. $(N=5)$. Significant difference from control values $(p<0.01)$ are shown by $*$. 
Table. Changes in heart rate (beats/minute)

\begin{tabular}{ccccc}
\hline Solvent & Normoxia & Hypoxia & Ethanol & Hypoxia+Ethanol \\
\hline None & $4.6 \pm 2.1$ & $21.9 \pm 6.7^{*}$ & $7.9 \pm 2.3$ & $41.5 \pm 4.6^{* *}$ \\
TCEL $(0.05 \mathrm{mM})$ & $15.8 \pm 4.0^{*}$ & $26.6 \pm 8.4^{*}$ & $14.4 \pm 4.9$ & $34.8 \pm 7.6^{* *}$ \\
TCEL $(0.1 \mathrm{mM})$ & $26.8 \pm 10.8^{*}$ & $27.3 \pm 9.3^{* *}$ & $21.0 \pm 9.5$ & $45.0 \pm 15.0^{* *}$ \\
PCEL $(0.1 \mathrm{mM})$ & $7.4 \pm 2.8$ & $17.8 \pm 4.2^{*}$ & $8.8 \pm 2.5$ & $30.2 \pm 5.8^{* *}$ \\
\hline
\end{tabular}

Each value represents preexposure heart rate minus heart rate at 45 minutes. All data are expressed as mean \pm S.E. $(N=2$ to 5$)$. Significant differences from control values are shown by $* *$ for $\mathrm{p}<0.01$ and $*$ for $\mathrm{p}<0.05$.

TCEL

In TCEL of $0.05 \mathrm{mM}$, as shown in Fig. 1, PQ prolongation observed in the combination of TCEL, hypoxia and ethanol was significant $(\mathrm{p}<0.01)$ while none of TCEL alone, TCEL with hypoxia, and TCEL with ethanol produced the marked change in the atrioventricular conduction. Changes in heart rate are presented in the 2 nd column of Table. TCEL alone elicited the significant change of heart rate, which was enhanced by hypoxia and the combination of hypoxia and ethanol. As shown in Fig. 2, dPQ/HR was significant only in the combination of TCEL, hypoxia and ethanol $(\mathrm{p}<0.01)$.

TCEL of $0.1 \mathrm{mM}$ elicited the more remarkable effect both on PQ interval and heart rate. PQ prolongation observed in TCEL alone was $8.2 \pm 1.27 \mathrm{msec}$ (mean \pm S.E.), which is not statistically significant. PQ prolongations observed in the hearts subjected to TCEL with hypoxia, TCEL with ethanol, and TCEL with hypoxia and ethanol were $10.7 \pm 0.83 \mathrm{msec}$ (mean of three hearts), $20.3 \pm 1.10 \mathrm{msec}$ (mean of three hearts), and $22.0 \pm 3.0 \mathrm{msec}$ (mean of two hearts), respectively. These values were all statistically significant $(p<0.01)$. Changes in heart rate are presented in the 3rd column of Table. In two hearts of TCEL with hypoxia, two hearts of TCEL with ethanol, and three hearts of TCEL with hypoxia and ethanol, the marked decrease of heart rates and flow rates made it impossible to continue the further observations.

In TCEL of $0.3 \mathrm{mM}$, even TCEL alone produced the significant prolongation of PQ intervals $(\mathrm{p}<0.01)$ for $18.0 \pm 2.0 \mathrm{msec}$ (mean of two hearts). Further, in TCEL alone of $0.5 \mathrm{mM}, 2: 1$ atrioventricular block was observed (Fig. 5).

PCEL

In PCEL of $0.05 \mathrm{mM}$, even under the coadministration of hypoxia and ethanol, PQ prolongation observed, which was $7.3 \pm 2.4 \mathrm{msec}$ (mean of three hearts), was not statistically significant. Change in heart rate under the coadministration of PCEL, ethanol, and hypoxia was $37.3 \pm 9.8$ beats/minute $(\mathrm{p}<0.01)$.

In PCEL of $0.1 \mathrm{mM}$, PQ prolongation observed under the coexistence of hypoxia and ethanol was significant $(\mathrm{p}<0.01)$ (Fig. 3). Changes in heart rate are shown in 4 th column of Table. The indicator of dPQ/HR was significant only 

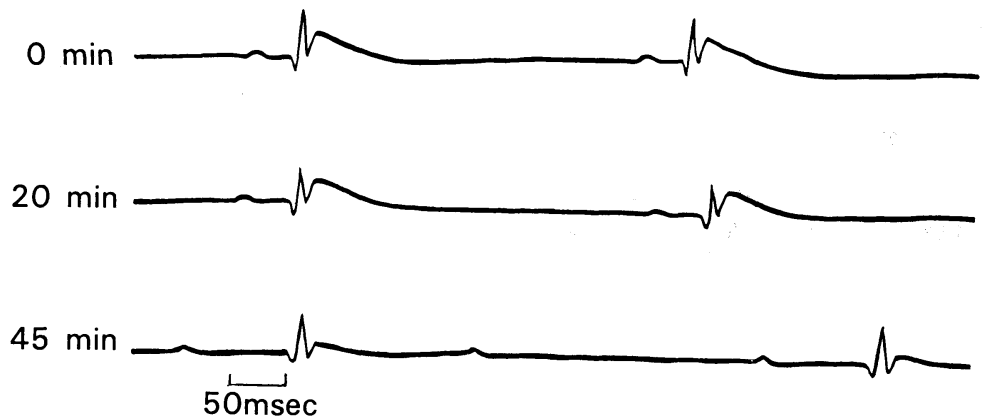

Fig. 5. 2:1 atrioventricular block observed in TCEL alone of $0.5 \mathrm{mM}$. Top, preexposure (heart rate $156 \mathrm{beats} / \mathrm{min}, \mathrm{PQ}$ interval $42 \mathrm{msec}$ ). Middle, 20 minutes of exposure (heart rate 140 beats/min, $P Q$ interval $50 \mathrm{msec}$ ). Bottom, 45 minutes of exposure, 2 : 1 atrioventricular block (heart rate 115 beats/min).

in the combination of PCEL, hypoxia and ethanol ( $\mathrm{p}<0.01$ ) (Fig. 4). It is considered that the effect on the heart conduction system is stronger in TCEL than in PCEL.

\section{Discussion}

In the present study, the evidence was obtained that tri- and tetra-chloroethylene have the direct and local effect on the heart conduction system which is enhanced by the interaction with hypoxia and ethanol.

In the previous studies, the cardiac sensitization, an increased susceptibility of the heart to catecholamines resulting in arrhythmias, has been investigated and discussed as the mechanism of the arrhythmogenicity of several organic solvents such as trichloroethylene, ${ }^{6)}$ tetrachloroethylene, ${ }^{2+)}$ and 1,1,1-trichloroethane. ${ }^{25)}$ However, the atrioventricular conduction prolongations observed in the present study are not due to the cardiac sensitization because the effect of the endogenous catecholamines can be excluded in the isolated perfused heart. Although it is known that acetaldehyde, the first breakdown product of ethanol, can induce the direct release of myocardial norepinephrine, ${ }^{26)}$ ethanol is not metabolized in the perfused rat heart. ${ }^{27)}$ Thus, our results obtained indicates that TCEL and PCEL have the direct and local effect on the heart conduction system.

It was noted that the interaction of TCEL/PCEL, ethanol and hypoxia on the atrioventricular conduction resulted in synergism (The term of synergism is used according to the definition of Doull et al. ${ }^{28)}$ ). The mechanism remains 
unclear. However, due to its lipophilic property, TCEL and PCEL have the possibility to affect the cell membrane directly. By using erythrocytes membrane, Korpela and Tahti found that TCEL influences the activities of the membrane bound enzymes such as ATPase and acetylcholine esterase. ${ }^{29,30)}$ Ethanol also inhibits the activities of ATPase of the cardiac plasma membrane. ${ }^{31}$ Further, it is known that hypoxia reduces ATP production and induces atrioventricular block by influencing the cell membrane of atrioventricular nodes. ${ }^{32}$ Therefore, it is likely that the synergistic interaction observed in the present study is due to the change in the activities of the cell membrane.

The relation between the blood concentration of TCEL/PCEL and its cardiac effect to man is not established. In an acute TCEL poisoning case, blood concentration of this compound was $0.17 \mathrm{mM}$ and no electrocardiographic change was described. ${ }^{9)}$ In the animal experiment, White et al. used TCEL of $0.3 \mathrm{mM}$ to produce the epinephrine-induced cardiac arrhythmias in rabbits. ${ }^{21}$ As for PCEL, in an acute poisoning case, blood concentration of this compound was $0.13 \mathrm{mM}$ and no arrhythmia was described. ${ }^{33)}$ Our finding revealed that under the coexistence of hypoxia and ethanol, TCEL of $0.05 \mathrm{mM}$ or PCEL of $0.1 \mathrm{mM}$ is enough concentration to affect the atrioventricular conduction of the perfused rat heart. Further, hypoxia used in our study is the mild degree because the release of lactate, an anaerobic metabolite, was not observed even under the hypoxic condition. ${ }^{23)}$ Although it should be noted that findings of animal experiments can not be extrapolated directly to man, our results raise the possibility that the exercises and alcohol drinkings can enhance the proarrhythmic action of TCEL and PCEL in man.

In conclusion, we observed the synergistic interaction of TCEL/PCEL, hypoxia and ethanol on the atrioventricular conduction in the perfused rat heart.

\section{ACKNOWLEDGMENTS}

We would like to express appreciation to Dr. S. Imamura and Dr. Y. Miyazaki, Department of Hygiene and Environmental Health, Faculty of Medicine, Tokyo Medical and Dental University, Japan for their valuable discussion and technical assistance during this study.

\section{REFERENCES}

1) Nomiyama $\mathrm{K}$, Nomiyama $\mathrm{H}$. Health effects of trichloroethylene in human subjects. Jpn J Ind Health 1979; 21: 311-33. (In Japanese)

2) Nishitani $\mathrm{H}$. A review of cases of intoxication due to trichloroethylene and tetrachloroethylene. Toxicol Forum 1984; 7: 247-55. (In Japanese)

3) Geiger AJ. Cardiac dysrhythmia and syncope from therapeutic inhalation of chlorinated hydrocarbons. JAMA 1943; 123: 141-4.

4) Waters RM, Orth OS, Gillespie NA. Trichloroethylene anesthesia and cardiac rhythm. Anesthesiology 1943; 4: 1-5. 
5) Barnes CG, Ives J. Electrocardiographic changes during trilene anesthesia. Proc Roy Soc Med 1944; 37: 528-32.

6) Kleinfeld M, Tabershaw IR. Trichloroethylene toxicity-report of five fatal cases. Arch Ind Hyg Occup Med 1954; 10: 134-41.

7) Norris W, Stuart P. Cardiac arrest during trichloroethylene anesthesia. Brit Med J 1957; 1: 860-3.

8) Thierstein ST, Hanigan JJ, Faul MD, Stuck PL. Trichloroethylene anesthesia in obstetrics. Obstetrics and Gynecology 1960; 15: 560-5.

9) James WRO. Fatal addiction to Trichloroethylene. Brit J Ind Med 1963; 20: 47-9.

10) Konietzko H, Elster I. Toxic effects on heart of trichloroethylene. Arch Toxicol 1973; 31: 93-8.

11) Dmochowska-Mroczek H. Serious arrhythmia in a case of acute intoxication with trichloroethylene. Kardiol Pol 1975; 15: 343-5.

12) Abedin Z, Cook FRC, Milberg RM. Cardiac toxicity of perchloroethylene (a dry cleaning agent). South Med J 1980; 73: 1081-3.

13) Nakamura K. Mortality pattern among cleaning workers. Jpn J Ind Health 1985; 27 : 24-37.

14) Resnik WH. Observations on the effect of anoxemia on the heart. I, Auriculo-ventricular conduction. J Clin Invest 1925; 2: 93-115.

15) Coffman JD, Lewis FB, Gregg DE. Effect of prolonged periods of anoxia on atrioventricular conduction and cardiac muscle. Circ Res 1960; 8: 649-59.

16) Taylor GJ. Cardiac arrhythmias in hypoxic rabbits during aerosol propellant inhalation. Arch Environ Health 1975; 30: 349-52.

17) Ettinger PO, Wu CF, Cruz CDL, Weisse AB, Ahmed SS, Regan TJ. Arrhythmia and the "Holiday Heart": Alcohol-associated cardiac rhythm disorders. Am Heart J 1978; 95: 555-62.

18) Williams ES, Morro MJ, Bailey JC. Electrophysiological effects of ethanol, acetaldehyde, and acetate on cardiac tissues from dog and guinea pig. Circ Res 1980; 47: 473-8.

19) Gilmour RF, Ruffy R, Lovelace DE, Muelier TM, Zipes DP. Effects of ethanol on electrogram changes and regional myocardial blood flow during acute myocardial ischemia. Cardiovasc Res 1981; 15: 47-58.

20) Greenspon AJ, Scaal SF. The "Holiday Heart": Electrophysiologic studies of alcohol effects in alcoholics. Ann Intern Med 1983; 98: 135-9.

21) White JF, Carlson GP. Epinephrine-induced cardiac arrhythmias in rabbits exposed to trichloroethylene: Potentiation by ethanol. Toxicol Appl Pharmacol 1981; 60: 466-71.

22) Takano T, Miyazaki Y, Araki R. A dual wavelength spectrophotometric measurement of carboxyhemoglobin in rat perfused heart. Jap J Ind Health 1981; 23: 424-5. (In Japanese)

23) Araki R, Tamura M, Yamazaki I. The effect of intracellular oxygen concentration on lactate release, pyridine nucleotide reduction, and respiration rate in the rat cardiac tissue. Circ Res 1983; 53: 448-55.

24) Reinhardt CF, Mullin LS, Maxfield ME. Epinephrine-induced cardiac arrhythmia potential of some common industrial solvents. J Occup Med 1973; 15: 953-5.

25 ) Kobayashi H, Hobara T, Hirata H, Higashihara E, Iwamoto S, Sakai T. Sensitization of dog myocardium to epinephrine by 1,1,1-trichloroethane. Jpn J Ind Health 1982; 24: 450-4. (In Japanese)

26) James TN, Bear ES. Effects of ethanol and acetaldehyde on the heart. Am Heart J 1967; 74: 243-55.

27) Lochner A, Cowley R, Brink AJ. Effect of ethanol on membrane and function of perfused rat heart. Am Heart J 1969; 78: 770-80.

28) Doull J, Klaassen CD, Amdur MO. Casarett and Doull's Toxicology: The basic science of poisons. 2nd ed. New York: MacMillan, 1980: 17-8. 
29) Korpela M, Tahti H. Effects of organic solvent on erythrocyte membrane acetylcholine esterase activity. Arch Toxicol Suppl 1985; 8: 148-51.

30) Tahti H, Korpola M. Neurotoxic effects of organic solvents. In: Recent advances in researches on the combined effects of environmental factors. Kanazawa: Kyoei, 1987; 637-53.

31) Williams JW, Tada M, Katz AM, Rubin E. Effect of ethanol and acetaldehyde on the $\mathrm{Na}^{+}, \mathrm{K}^{+}$activated ATPase activity of cardiac plasma membrane. Biochem Pharmacol 1975; 24: 27-32.

32) Ikeda N, Toyama J. Mechanism of atrioventricular block and bundle block. Medicina Philosophica 1986; 5: 348-54. (In Japanese)

33) Koeppel C, Arendt U, Koeppe P. Acute tetrachloroethylene poisoning - blood elimination kinetics during hyperventilation therapy. Clinic Toxicol 1985; 23: 103. 